\title{
Menurunkan Skala Nyeri Bayi Prematur melalui Facilitated Tucking disertai 'Hadir-Berbicara' sebagai Upaya Penerapan Teori Comfort Kolcaba
}

\author{
Nopi Nur Khasanah ${ }^{1,2}$, Yeni Rustina ${ }^{3}$ \\ ${ }^{1}$ Fakultas IImu Keperawatan, Universitas Islam Sultan Agung, Semarang 50112, Indonesia \\ 2Prodi Magister Spesialis Keperawatan Anak, Fakultas IImu Keperawatan, \\ Universitas Indonesia, Depok 16424, Indonesia \\ ${ }^{3}$ Fakultas IImu Keperawatan, Universitas Indonesia, Depok 16424, Indonesia \\ Email: nopi.khasanah@unissula.ac.id
}

\begin{abstract}
Abstrak
Pengalaman nyeri pada bayi prematur yang berada di ruang perawatan bayi risiko tinggi terjadi setiap hari selama perawatan berlangsung. Perawat perlu melakukan sebuah intervensi untuk menurunkan skala nyeri bayi prematur. Manajemen nyeri harus dilakukan sejak bayi lahir karena prosedur menyakitkan yang terus berulang pada tahap awal kehidupan dapat merusak perkembangan sistem saraf pusat secara permanen. Studi ini bertujuan untuk menggambarkan penerapan teori Comfort Kolcaba melalui intervensi facilitated tucking disertai 'hadir-berbicara' pada bayi prematur yang dirawat di ruang perawatan bayi risiko tinggi. Penelitian ini menggunakan metode studi kasus dengan mengaplikasikan empat konteks kenyamanan dikaitkan dengan tiga tipe kenyamanan berdasarkan teori Comfort Kolcaba dalam pemberian asuhan keperawatan pada lima bayi prematur yang mendapatkan berbagai prosedur menyakitkan. Intervensi keperawatan melalui facilitated tucking disertai 'hadir-berbicara' berdasarkan prinsip teori Comfort Kolcaba memberikan hasil yang positif terhadap tingkat kenyamanan bayi prematur. Empat dari lima bayi prematur berada dalam tingkat transcendence yang merupakan tipe kenyamanan tertinggi setelah ease dan relief. Teori Comfort Kolcaba dapat diterapkan dalam lingkup perawatan neonatal karena sesuai dengan asuhan perkembangan dan mampu menurunkan skala nyeri bayi prematur.
\end{abstract}

Kata Kunci: bayi premature, facilitated tucking, hadir-berbicara, teori comfort

\section{Reducing The Scale of Pain on Premature Infants Using Facilitated Tucking Accompanied with 'Being with-Talking to' Techniques in An Effort of Applying Kolcaba Comfort's Theory}

\begin{abstract}
Premature infants had been experience of pain in neonatal ward that occur each day during treatment. Nurse need to do an intervention for reduce the scale of pain on premature infants. Pain management have to do at birth because of the repeated painful procedures in early life can affect the development of central nerve system permanently. The objective of this study was to describe the application of Kolcaba Comfort's theory through facilitated tucking accompanied with 'being with-talking to' techniques in premature's infant at high risk infant care. The method that used was case study by applying the four contexts of comfort's experience associated with the three types of comfort based on Kolcaba Comfort's theory in providing nursing care on five premature infants who have some painful procedures. The nursing intervention through facilitated tucking accompanied by 'being with-talking to' based on the principles of Kolcaba Comfort's theory gave a positive result against premature infants's comfort level. Four from five premature infants are in the level of transcendence which is a type of supreme comfort after the ease and relief. Kolcaba Comfort's theory can be applied within the scope of neonatal care due in accordance with the developmental care of the infants and could reduce the scale of pain.
\end{abstract}

Keywords: premature's infant, facilitated tucking, being with-talking to, comfort's theory

Info Artikel:

Artikel dikirim pada 31 Maret 2017

Artikel direvisi pada 05 Juli 2017

Artikel diterima pada 12 September 2017

DOI : http://dx.doi.org/10.21927/jnki.2017.5(2).83-90 


\section{PENDAHULUAN}

Tujuan utama dilakukan perawatan pada bayi baru lahir adalah mengurangi terjadinya stres akibat lingkungan dan nyeri pada bayi baru lahir terutama bayi yang lahir premature (1). Namun bayi prematur sering mendapat pengalaman nyeri secara periodik dari berbagai prosedur menyakitkan (2). Prosedur menyakitkan yang sering dilakukan antara lain prosedur penusukan tumit, pemeriksaan Retinophaty of Prematurity (ROP), pemasangan infus dan berbagai prosedur perawatan luka.

Prosedur tindakan menyakitkan dan terus berulang yang terjadi pada tahap awal kehidupan dapat merusak perkembangan sistem saraf pusat secara permanen (3). Manajemen nyeri yang tidak memadai dan distress yang terjadi selama prosedur invasif pada bayi secara permanen dapat menurunkan toleransi nyeri, meningkatkan respon nyeri sejalan dengan bertambahnya usia dan berkontribusi pada perkembangan nyeri kronis. Tenaga kesehatan perlu melakukan manajemen nyeri pada saat prosedur tindakan sejak saat bayi dilahirkan (2).

Manajemen nyeri dapat dilakukan dengan teknik farmakologi maupun non-farmakologi. Upaya non-farmakologi yang telah dilakukan untuk menurunkan nyeri bayi prematur yang digunakan pada studi ini adalah metode facilitated tucking disertai 'hadir-berbicara' berdasarkan prinsip teori Comfort Kolcaba. Facilitated tucking dilakukan dengan cara memfasilitasi bayi dalam posisi fleksi fisiologis, sedangkan intervensi 'hadir-berbicara' yang dilakukan oleh perawat diyakini mampu memenuhi kebutuhan emosional bayi prematur. Studi yang telah dilakukan sebelumnya dengan intervensi tersebut dapat meningkatkan kenyamanan bayi prematur. Oleh karena itu, perawat dapat menggunakan intervensi tersebut dalam setiap prosedur yang dapat menimbulkan nyeri atau ketidaknyamanan pada bayi prematur.

Studi kasus ini dilakukan dengan mengembangkan profesionalisme dalam memberikan asuhan keperawatan melalui penerapan teori Comfort yang dikemukakan oleh Kolcaba untuk menurunkan skala nyeri dan/atau meningkatkan kenyamanan bayi prematur yang mendapatkan berbagai prosedur menyakitkan. Kenyamanan pasien merupakan hal utama pada teori Comfort, oleh karenanya metode yang akan digunakan pada studi ini dilakukan dengan mengkombinasikan dua metode nonfarmakologi, yaitu facilitated tucking disertai 'hadirberbicara', masing-masing metode tersebut pada studi sebelumnya terbukti meningkatkan kenyamanan bayi prematur.

\section{BAHAN DAN METODE}

Studi ini menggunakan desain studi kasus. Kasus yang diambil sebanyak lima. Studi dilakukan pada bulan Februari sampai April 2016. Sampel dalam studi ini adalah bayi prematur yang dirawat di ruang perawatan bayi risiko tinggi RSCM. Data

Tabel 1. Pengkajian Kenyamanan berdasarkan Struktur Taksonomi Kolcaba pada Tiap Kasus di RSCM (Februari-April, 2016)

\begin{tabular}{|c|c|c|c|c|c|}
\hline \multirow[t]{2}{*}{$\begin{array}{c}\text { Konteks } \\
\text { Kenyamanan }\end{array}$} & \multicolumn{5}{|c|}{ Tipe Kenyamanan: Relief/Ease/Trancendence } \\
\hline & Bayi Satu & Bayi Dua & Bayi Tiga & Bayi Empat & Bayi Lima \\
\hline \multicolumn{6}{|l|}{ Kenyamanan Fisik } \\
\hline Jenis Kelamin & Laki-Laki & Perempuan & Laki-Laki & Perempuan & Laki-Laki \\
\hline Usia Gestasi & 35 Minggu & 30 Minggu & 34 Minggu & 36 Minggu & 30 Minggu \\
\hline Kondisi Bayi & $\begin{array}{c}\text { Lemah (8 } \\
\text { diagnosis medis) }\end{array}$ & $\begin{array}{c}\text { Lemah (7 } \\
\text { diagnosis medis) }\end{array}$ & $\begin{array}{c}\text { Lemah (8 } \\
\text { diagnosis medis) }\end{array}$ & $\begin{array}{c}\text { Lemah (6 } \\
\text { diagnosis medis) }\end{array}$ & $\begin{array}{c}\text { Lemah (8 } \\
\text { diagnosis medis) }\end{array}$ \\
\hline Berat Lahir & 3740 gram & 1450 gram & 1840 gram & 2700 gram & 1524 gram \\
\hline Berat Sekarang & 3740 gram & 2390 gram & 1840 gram & 2640 gram & 1372 gram \\
\hline Hari Rawat Ke- & 4 & 64 & 1 & 1 & 14 \\
\hline $\begin{array}{l}\text { Karakteristik } \\
\text { Nyeri }\end{array}$ & $\begin{array}{c}\text { Heelprick } \\
\text { (skor nyeri 10) }\end{array}$ & $\begin{array}{c}\text { Perawatan luka } \\
\text { (skor nyeri 13) }\end{array}$ & $\begin{array}{c}\text { Heelprick } \\
\text { (skor nyeri 11) }\end{array}$ & $\begin{array}{l}\text { Pemasangan infus } \\
\text { (skor nyeri 12) }\end{array}$ & $\begin{array}{c}\text { Pemeriksaan ROP } \\
\text { (skor nyeri 9) }\end{array}$ \\
\hline $\begin{array}{l}\text { Kenyamanan } \\
\text { Lingkungan }\end{array}$ & \multicolumn{5}{|c|}{ Kebisingan dari tim kesehatan dan alat, cahaya telah minimal karena terdapat penutup inkubator } \\
\hline $\begin{array}{l}\text { Kenyamanan } \\
\text { Sosiokultural }\end{array}$ & \multicolumn{5}{|c|}{ Orangtua telah terlibat dalam perawatan, kecuali Bayi Satu dan Bayi Empat } \\
\hline $\begin{array}{l}\text { Kenyamanan } \\
\text { Psikospiritual }\end{array}$ & \multicolumn{5}{|c|}{$\begin{array}{l}\text { Orangtua belum percaya diri, namun mempunyai motivasi untuk merawat bayi prematur secara } \\
\text { mandiri }\end{array}$} \\
\hline
\end{tabular}

Sumber Data: Hasil Observasi Peneliti, 2016 
didapatkan dari catatan medis dan keperawatan serta asuhan keperawatan dan observasi secara langsung menggunakan Premature Infant Pain Profile (PIPP).

\section{HASIL DAN BAHASAN}

Hasil studi kasus ini memaparkan ringkasan riwayat asuhan keperawatan yang diberikan pada lima pasien kelolaan yang mendapatkan berbagai prosedur menyakitkan. Kasus-kasus ini meliputi asuhan keperawatan pada bayi yang lahir prematur dengan berbagai latar belakang masalah medis yang berbeda. Namun memiliki masalah keperawatan yang sama yaitu ketidaknyamanan: nyeri akut.

Tabel 1 menunjukkan hasil pengkajian berdasarkan struktur taksonomi Kolcaba pada lima bayi prematur, yang meliputi empat konteks kenyamanan (fisik, lingkungan, sosiokultural, dan psikospiritual) dikaitkan dengan tipe kenyamanan (relief, ease, transcendence) dimana kelima bayi prematur berada pada tingkat kenyamanan relief.

Selanjutnya dipaparkan skema 1 terkait integrasi teori Comfort Kolcaba dalam asuhan keperawatan pada bayi prematur yang mengalami nyeri prosedural. Dibutuhkan sebuah intervensi untuk menurunkan pengalaman nyeri pada bayi prematur yang memiliki sistem organ belum matang. Pengalaman nyeri tersebut menurut teori Comfort meliputi pengalaman fisik, psikospiritual, sosiokultural, dan lingkungan. Oleh karena itu dibutuhkan intervensi keperawatan untuk meningkatkan rasa nyaman bayi prematur, antara lain dengan metode facilitated tucking disertai 'hadirberbicara'. Berdasarkan teori Comfort, perawat juga perlu memperhatikan variabel yang mempengaruhi kenyamanan, sehingga intervensi yang dilakukan dapat maksimal dan mencapai kenyamanan pasien. Tercapainya kenyamanan pada bayi prematur, diharapkan dapat mengoptimalkan pertumbuhan dan perkembangan bayi, sehingga keluarga akan merasa puas dengan pelayanan rumah sakit.

Penerapan teori Comfort dalam bentuk rangkaian proses keperawatan dari masalah nyeri/ ketidaknyamanan yang disebabkan oleh berbagai prosedur perawatan, diagnosis maupun prosedur invasif dilakukan mulai dari tahap pengkajian, analisis data untuk menentukan diagnosis keperawatan yang tepat, penyusunan intervensi, tahap implementasi dari intervensi yang telah disusun sebelumnya, serta tahap evaluasi yang mengacu pada outcome dari masing-masing diagnosis keperawatan. Struktur taksonomi untuk melakukan pengkajian keperawatan terkait kenyamanan meliputi tipe kenyamanan fisik, psikospiritual, sosiokultural, dan lingkungan (4).

Pengkajian kenyamanan fisik terkait dengan keluhan utama, isyarat dan perilaku bayi prematur yang menunjukkan ketidaknyamanan secara fisik. Data yang diperoleh melalui observasi isyarat perilaku bayi maupun pemeriksaan fisik pada kelima kasus kelolaan bervariasi terlihat dari usia gestasi, berat badan lahir maupun berat badan saat pengkajian, jenis kelamin, lama rawat inap, kondisi bayi prematur, serta karakteristik prosedur menyakitkan.

Usia gestasi bayi prematur yang terpilih dalam kasus ini berkisar antara 30 minggu sampai 36 minggu. Kasus dua dan lima dengan kelahiran pada usia gestasi 30 minggu termasuk dalam kategori prematuritas berat (7). Prosedur menyakitkan paling banyak dilakukan pada bayi dengan usia gestasi termuda (8). Pernyataan ini sesuai dengan Kasus dua yang termasuk dalam kategori prematuritas berat dan memiliki riwayat penyakit yang banyak dan lama rawat inap yang lama, sehingga berbagai prosedur menyakitkan pernah didapat oleh Kasus dua.

Kondisi bayi prematur berkaitan dengan kemampuan bayi untuk berespon terhadap nyeri. Kondisi bayi saat pengkajian juga berbeda pada masing-masing kasus, tidak hanya masalah ketidaknyamanan: Nyeri akut prosedural yang terjadi pada bayi. Temuan pada analisis kasus ini menyebutkan bahwa bayi dengan sakit parah mempunyai sedikit kemampuan untuk menunjukkan respon perilaku terhadap nyeri (9).

Berat badan lahir dari kelima kasus rata-rata sesuai dengan masa kehamilan, kecuali Kasus pertama yang berat badan lahirnya lebih besar dari masa kehamilan. Berat badan lahir dari kelima kasus rata-rata berada dalam klasifikasi berat lahir rendah (1.500 gram-2.500 gram), kecuali pada Kasus dua yang masuk dalam kategori berat lahir sangat rendah dan Kasus satu dalam kategori berat normal namun lebih besar dari masa kehamilan (10).

Jenis kelamin pada lima kasus paling banyak laki-laki. Badr menyebutkan, bahwa perbedaan jenis kelamin dapat berpengaruh pada respon perilaku bayi premature (11). Bayi prematur laki-laki cenderung kurang ekspresif dibandingkan bayi prematur yang berjenis kelamin perempuan.

Rentang lama rawat inap pada kelima kasus berkisar antara hari perawatan pertama sampai hari perawatan ke-64. Lama rawat inap ini berhubungan dengan pengalaman bayi prematur terhadap 


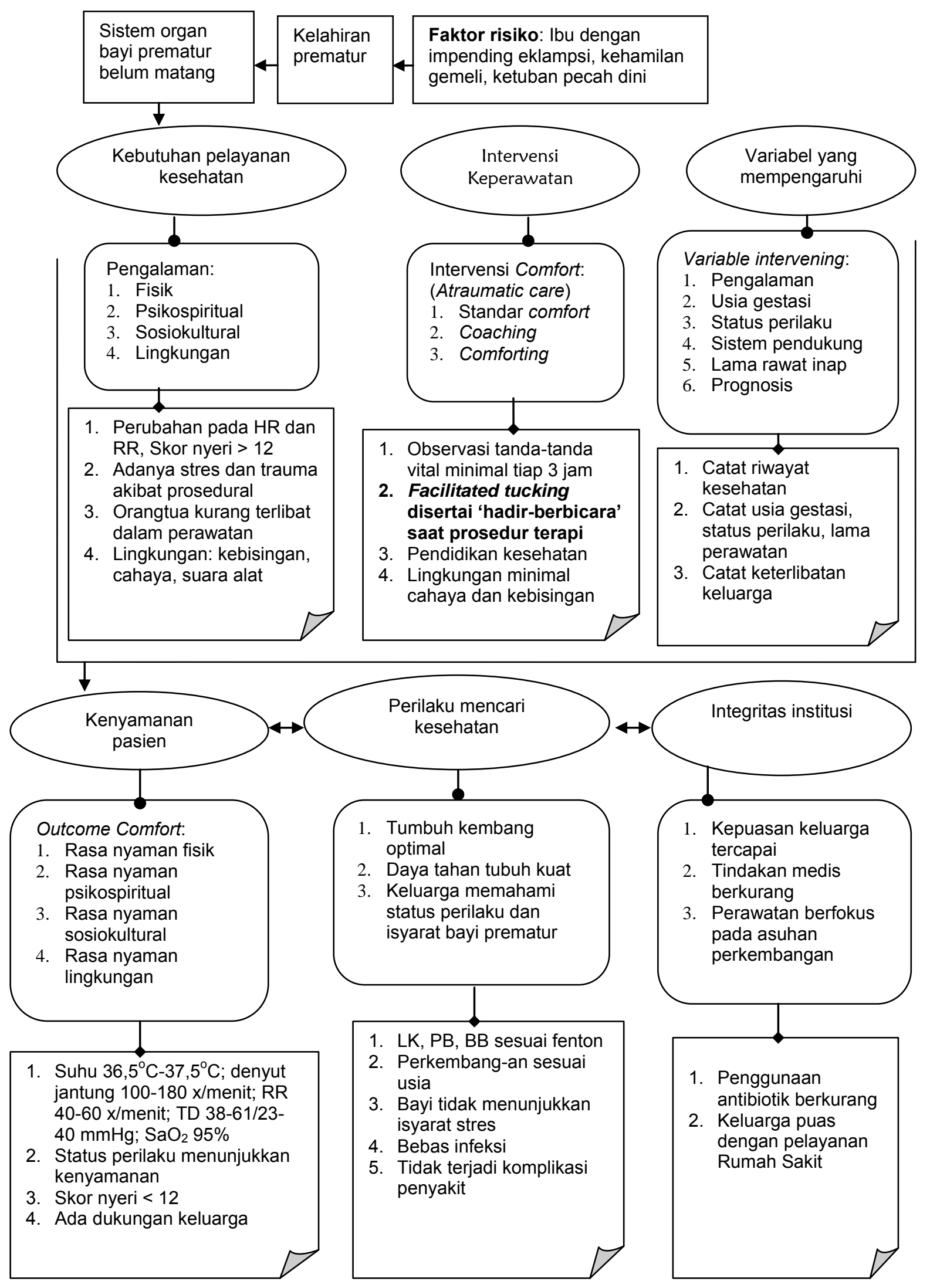

Gambar 1. Integrasi Teori Comfort Kolcaba dalam Asuhan Keperawatan pada Bayi Prematur yang Mengalami Nyeri Prosedural

Sumber: (4); (5); (6) 
respon nyeri dari berbagai stressor yang didapat sebelumnya, baik nyeri akibat prosedural, perawatan rutin maupun lingkungan. Nyeri berulang yang terjadi pada bayi prematur dapat menyebabkan kerusakan perkembangan otak (12). Hal inilah yang menjadi dasar agar tim kesehatan di ruang rawat neonatus menerapkan asuhan perkembangan sehingga perkembangan bayi dapat optimal dan menurunkan lama rawat inap.

Pada kelima kasus seluruhnya mengalami gangguan pemenuhan kebutuhan rasa nyaman: Nyeri akibat berbagai prosedur menyakitkan. Prosedur tersebut antara lain prosedur diagnostik yaitu pemeriksaan ROP, prosedur perawatan yaitu perawatan luka dermatitis, serta prosedur invasif yaitu penusukan tumit dan pemasangan infus.

Pada kelima kasus, Ners dapat melakukan pengkajian psikospiritual pada semua kasus. Psikis orangtua berperan dalam meningkatkan kenyamanan bayi (13). Bayi membutuhkan 'containment' yang hanya dapat terjadi jika pengasuh mampu memahami apa yang dibutuhkan oleh bayi premature (14). Artinya jika pengasuh percaya diri dan termotivasi dalam merawat bayi terutama dalam hal mengenali isyarat bayi maka dapat terbentuk 'containment' dan bayi akan mencapai kenyamanan.

Pada pengkajian sosiokultural secara umum orangtua berusaha terlibat dalam perawatan kecuali pada Kasus satu dan empat. Pada Kasus lima setiap hari mendapat kunjungan dari ibu dan seringkali lengkap dikunjungi oleh kedua orangtua. Kasus tiga dan kasus dua lebih sering dikunjungi oleh ibu. Seluruh ibu mampu berinteraksi dengan bayinya. Pengkajian secara kultural pada kelima kasus didapatkan data bahwa tidak ada tradisi/adat/ budaya/keyakinan agama yang bertentangan dengan pengobatan dan perawatan.

Pengkajian ketidaknyamanan lingkungan yang terlihat pada bayi adalah adanya kebisingan dari suara alat/inkubator yang dipindahkan maupun yang berbunyi dan suara tim kesehatan sendiri. Bayi seringkali tampak respon terkejut yang berlebihan saat mendengar ada kebisingan. Ketidaknyamanan pada ibu terlihat pada saat ibu ingin melakukan PMK dan/atau belajar meneteki karena dalam satu ruangan seringkali ada pria yang bukan suaminya tetapi salah satu tim kesehatan maupun ayah dari bayi lain yang satu ruangan dengan bayinya.

Pada kelima kasus muncul diagnosis keperawatan nyeri akut saat dilakukan tindakan/ prosedur menyakitkan. Masalah lain yang muncul adalah adanya ketidakseimbangan nutrisi kurang dari kebutuhan tubuh pada hampir semua kasus serta munculnya masalah gangguan termoregulasi baik yang masih risiko maupun yang aktual telah mengalami hipertermi/hipotermi.

Intervensi utama yang dilakukan Ners Spesialis Keperawatan Anak adalah facilitated tucking disertai 'hadir berbicara'. Intervensi ini kemudian disosialisasikan pada Ners yang bekerja di Ruang Perawatan Bayi Risiko Tinggi setelah terbukti efektif. Namun, observasi selama praktik belum semua Ners melakukan intervensi ini saat mendampingi pasien kelolaannya. Ners NICU di Korea seringkali tidak optimal dalam melaksanakan manajemen nyeri termasuk menggunakan alat pengkajian nyeri (15). Ners Spesialis Keperawatan Anak merekomendasikan perlunya melakukan studi lebih lanjut terkait persepsi Ners NICU di Indonesia terhadap nyeri bayi prematur agar dapat dilakukan upaya untuk memaksimalkan manajemen nyeri.

Selain akibat prosedural, ketidaknyamanan pada lima kasus bayi prematur juga terjadi karena adanya gangguan termoregulasi, nutrisi dan pernapasan. Pada gangguan termoregulasi, Ners Spesialis Keperawatan Anak berupaya menjaga suhu tubuh bayi stabil dengan mengatur suhu inkubator dan membantu ibu untuk perawatan metode kanguru (PMK). Pada gangguan pernapasan, Ners Spesialis Keperawatan Anak melakukan isap lendir dengan meminta bantuan rekan untuk melakukan facilitated tucking disertai 'hadir-berbicara'. Pada masalah nutrisi, Ners Spesialis Keperawatan Anak memberikan posisi lateral kanan dan/atau pronasi setelah pemberian nutrisi serta memfasilitasi ibu untuk PMK agar tercipta bonding, melatih reflek isap serta terjadi keseimbangan termoregulasi.

Setelah dilakukan tindakan keperawatan selama dua minggu pada kelima kasus, satu diantaranya pulang sedangkan empat yang lain masih dalam perawatan untuk proses peningkatan berat badan serta edukasi pada ibu agar percaya diri dalam merawat bayinya di rumah.

Tipe kenyamanan relief berdasarkan teori Comfort Kolcaba dapat dikatakan sebagai tingkat rasa nyaman yang paling rendah, antara lain dapat terlihat dari adanya skor nyeri pada kelima kasus. Peningkatan kenyamanan bayi prematur akan terlihat pada Tabel 2. Adapun hasil evaluasi pada kelima kasus dilakukan oleh Ners dengan dasar evaluasi berikut pada Tabel 2. 
Tabel 2. Evaluasi Keperawatan berdasarkan Struktur Taksonomi Kolcaba di RSCM (Februari-April, 2016)

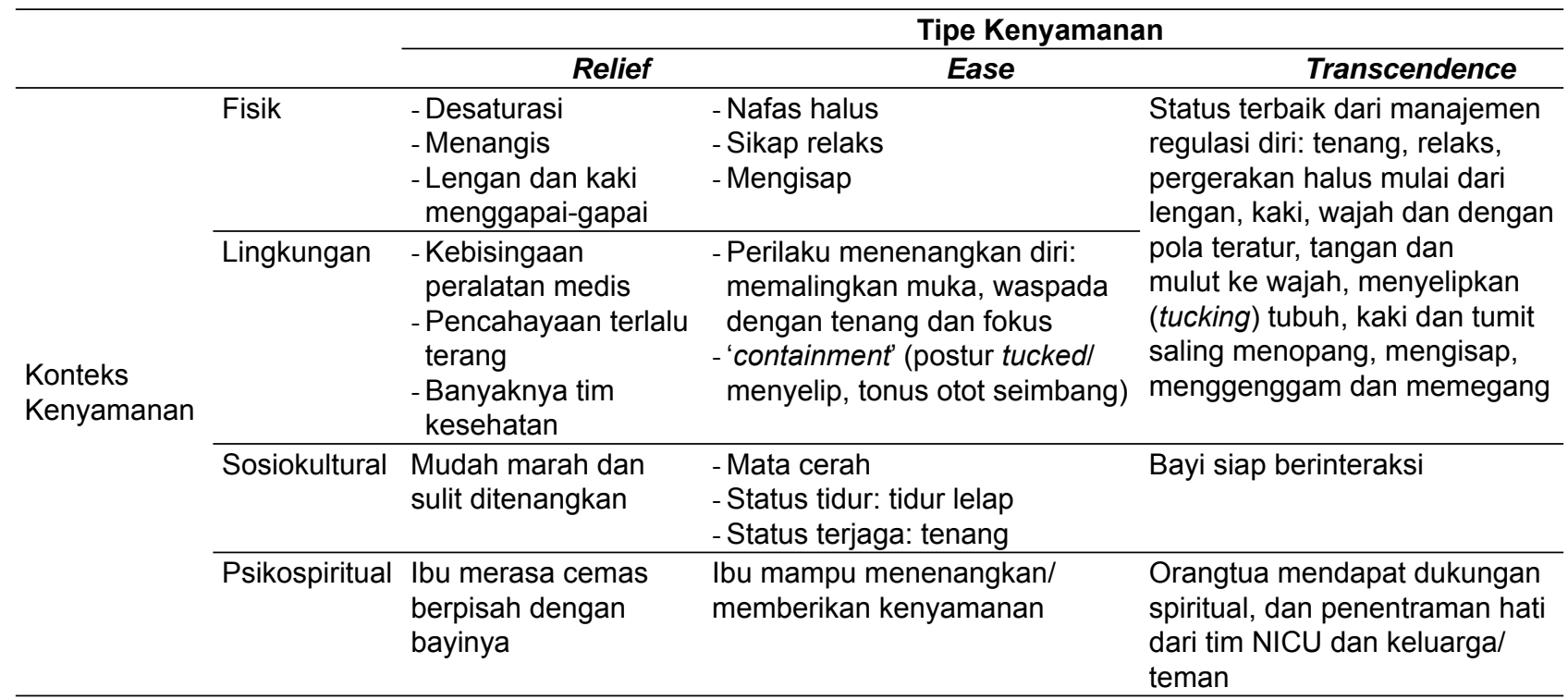

Sumber: (16); (17)

Hasil evaluasi pada kelima kasus setelah 14 hari perawatan berada pada tingkat kenyamanan transcendence yang menurut teori Comfort Kolcaba merupakan tingkat kenyamanan tertinggi, dimana kelima bayi tidak merasa nyeri, bahkan berada pada status terbaik dari manajemen regulasi diri. Terlihat dari konteks kenyamanan fisik maupun lingkungan, bayi tenang dan relaks. Pada konteks kenyamanan sosiokultural, bayi tampak siap berinteraksi baik dengan perawat maupun orangtua. Pada konteks kenyamanan psikospiritual, orangtua bayi mendapat dukungan spiritual, dan penentraman hati dari tim $\mathrm{NICU}$ dan anggota keluarga lain maupun temannya. Hal ini membuktikan bahwa intervensi non-farmakologi dengan metode facilitated tucking disertai 'hadirberbicara' efektif dalam meningkatkan kenyamanan bayi prematur dengan menurunkan skor nyeri bayi.

Facilitated tucking merupakan salah satu intervensi non-farmakologis untuk menurunkan persepsi nyeri bayi prematur yang terbukti efektif dalam menghilangkan nyeri akut pada neonates (18-20). Facilitated tucking didefinisikan sebagai penahanan lengan dan kaki bayi dalam tertekuk, posisi garis tengah dekat dengan tenggorokan (posisi fleksi fisiologis/midline position). Teknik memegangnya dapat berbeda tergantung prosedur menyakitkan yang akan dilakukan pada bayi premature (21). "Hadir-berbicara" pada bayi sebagai bagian dari perawatan neonatal yang telah diidentifikasi sebagai aspek penting dari manajemen nyeri meskipun belum banyak penelitian tentang suara pengasuh. Namun
Schore, membuktikan bahwa hubungan dengan orang dewasa sangat penting untuk memfasilitasi pertumbuhan otak bayi agar mampu mengelola stress (22). Pada saat stres bayi sangat membutuhkan dukungan dari pengasuh dewasa untuk membantu mereka mengatur keadaan emosional mereka.

\section{SIMPULAN DAN SARAN}

Teori Comfort Kolcaba dapat diterapkan pada asuhan keperawatan bayi prematur dengan masalah nyeri prosedural karena memenuhi semua aspek kebutuhan rasa nyaman. Pemenuhan kebutuhan rasa nyaman tersebut meliputi kenyamanan fisik, psikospiritual, sosiokultural, dan lingkungan.

Analisis penerapan teori Comfort Kolcaba melalui intervensi facilitated tucking disertai 'hadirberbicara' pada kelima kasus mampu memberikan rasa nyaman pada bayi prematur yang mengalami nyeri prosedural. Pada akhir perawatan pada kelima kasus, bayi prematur berada dalam tahap kenyamanan transcendence. Bayi tidak mengalami nyeri dan berada dalam status terbaik dari manajemen regulasi diri bayi.

Tindak lanjut dari studi ini adalah bahwa teknik facilitated tucking disertai 'hadir-berbicara' pada bayi prematur dapat diimplementasikan oleh perawat ruangan sebagai standar dalam mendampingi bayi yang mendapatkan prosedur menyakitkan. Teknik ini dapat dilakukan pada bayi prematur yang mendapatkan prosedur rutin seperti penusukan tumit, 
pemeriksaan ROP, hisap lendir, pemasangan infus, awal pemasangan ETT dan prosedur rutin lainnya. Perawat ruangan dapat melibatkan keluarga untuk melakukan facilitated tucking sebagai implementasi family centered care.

\section{RUJUKAN}

1. Aita $M$, Goulet $C$, Oberlander TF, Snider L, Johnston C. A randomized controlled trial of eye shields and earmuffs to reduce pain response of preterm infants. J Neonatal Nurs [Internet]. 2015 Jun;21(3):93-103. Available from: http://linkinghub.elsevier.com/retrieve/pii/ S1355184114001598

2. Gomella TL, Cunningham MD, Eyal FG. Neonatology: Management, proceures, on-call problems, diseases, and drugs. 7th ed. New York: Mc Graw Hill Education; 2013.

3. Hatfield LA, Meyer MA, Messing TM. A systematic review of the effects of repeated painful procedures in infants: Is there a potential to mitigate future pain responsivity? J Nurs Educ Pract [Internet]. 2013 Jan 24;3(8). Available from: http://www.sciedu.ca/ journal/index.php/jnep/article/view/1802

4. Kolcaba K, DiMarco MA. Comfort Theory and its application to pediatric nursing. Pediatr Nurs [Internet]. 31(3):187-94. Available from: http:// www.ncbi.nlm.nih.gov/pubmed/16060582

5. Alligood MR, Tomey AM. Nursing theorist and their work. St. Louis Missouri: Mosby Elsevier; 2010.

6. Hockenberry MJ, Wilson D. Wong's essentials of pediatric nursing. 8th ed. St. Louis Missouri: Mosby Elsvier; 2009.

7. Ball J, Bindler R, Cowen K. Child health nursing, partnering withchildren \& families. 2nd ed. New Jersey: Pearson Education inc.; 2010.

8. Carbajal R, Rousset A, Danan C. Epidemiology and treatment of painful procedures in neonates in intensive care units. JAMA. 2008;300(1):60-70.

9. Gibbins S, Stevens B, McGrath PJ, Yamada J, Beyene J, Breau L, et al. Comparison of pain responses in infants of different gestational ages. Neonatology [Internet]. 2008;93(1):10-8. Available from: http://www.ncbi.nlm.nih.gov/ pubmed/17630493

10. Rustina Y. Bayi prematur: Perspektif keperawatan. Jakarta: Sagung Seto; 2015.

11. Badr LK. Pain in Premature Infants: What Is Conclusive Evidence and What Is Not. Newborn Infant Nurs Rev [Internet]. 2013 Jun;13(2):82-6.
Available from: http://linkinghub.elsevier.com/ retrieve/pii/S1527336913000251

12. Ranger M, Grunau RE. Early repetitive pain in preterm infants in relation to the developing brain. Pain Manag [Internet]. 2014 Jan;4(1):57-67. Available from: http://www.ncbi.nlm.nih.gov/ pubmed/24641344

13. Khasanah NN, Rustina Y, Syahreni E. Improving interaction between mother and premature infant through educational video and identification practice of premature infant's cues. International Nursing Confrence. 2015.

14. Zwimpfer L, Elder D. Talking to and being with babies : the nurse - infant relationship as a pain management tool. 2012;15(3).

15. Jeong IS, Park SM, Lee JM, Choi YJ, Lee J. Perceptions on Pain Management among Korean Nurses in Neonatal Intensive Care Units. Asian Nurs Res (Korean Soc Nurs Sci) [Internet]. 2014 Dec;8(4):261-6. Available from: http://linkinghub. elsevier.com/retrieve/pii/S1976131714000735

16. Williamson K. Comfort theory: A guided for practice of neonatal nursing. J Chem Inf Model. 2013;53(9):1689-99.

17. Vandenberg K, Browne J V, Ph D, Perez L, Ph D, Newstetter A. Getting to know your baby. Oakland: Mills Collage, Department of Education; 2003.

18. Cignacco EL, Sellam G, Stoffel L, Gerull R, Nelle $M$, Anand KJS, et al. Oral Sucrose and "Facilitated Tucking" for Repeated Pain Relief in Preterms: A Randomized Controlled Trial. Pediatrics [Internet]. 2012 Feb 1;129(2):299-308. Available from: http:// pediatrics.aappublications.org/cgi/doi/10.1542/ peds.2011-1879

19. Liaw J-J, Yang L, Katherine Wang K-W, Chen C-M, Chang Y-C, Yin T. Non-nutritive sucking and facilitated tucking relieve preterm infant pain during heel-stick procedures: A prospective, randomised controlled crossover trial. Int J Nurs Stud [Internet]. 2012 Mar;49(3):300-9. Available from: http://linkinghub.elsevier.com/retrieve/pii/ S0020748911003725

20. Lopez O, Subramanian P, Rahmat N, Theam LC, Chinna K, Rosli R. The effect of facilitated tucking on procedural pain control among premature babies. J Clin Nurs [Internet]. 2015 Jan;24(1-2):183-91. Available from: http://doi. wiley.com/10.1111/jocn. 12657

21. Kucukoglu S, Kurt S, Aytekin A. The effect of the facilitated tucking position in reducing vaccination- 
induced pain in newborns. Ital J Pediatr [Internet]. 2015 Dec 21;41(1):61. Available from: http://www. ijponline.net/content/41/1/61

22. Zwimpfer L, Elder D. Talking to and being with babies: The nurse-infant relationship as a pain management tool. Neonatal, Paediatr Child Heal Nurs [Internet]. 2012 [cited 2017 Sep 12];15(3):10-4. Available from: https://search. informit.com.au/documentSummary; $d n=245007$ 495088948;res=IELHEA 